\title{
Popularização da sustentabilidade: análise de uma integração ensino médio-graduação
}

\author{
Daniel Baron ${ }^{1}$, Carlos Gustavo Momberg da Silva², Sandra Cristina Oliveira Almeida², Meire \\ Maria Cordeiro33, Ester Almeida Helmer ${ }^{3}$
}

Resumo: Neste estudo nosso objetivo foi analisar contextos de aprendizagem propiciados por um projeto de colaboração entre Universidade/Escola Pública, empregando como tema norteador conceitos sobre a produção vegetal sustentável. Esta proposta envolveu estudantes universitários na popularização da ciência sobre a necessidade de otimizar os recursos naturais disponíveis, bem como a reciclagem de materiais descartados, a partir do aperfeiçoamento de professores e de estudantes do ensino médio público. O compartilhamento dialógico entre os estudantes de ambas as instituições de ensino possibilitou a experimentação de novos modos e ações, a fim de solucionar problemas como a armazenamento de águas pluviais, compostagem de restos de merenda escolar e reutilização de materiais reciclados para confecção de sistema hidropônico para o cultivo de hortaliças e plantas medicinais.

Palavras-chave: Águas pluviais; Compostagem; Hidroponia; Reaproveitamento

\section{Popularization of sustainability: analysis of a high school-college integration}

Abstract: This study aimed to analyze learning contexts provided by a collaborative project between High School and college using concepts on sustainable vegetable production as guiding theme. This proposal involved university students in the popularization of science on the need for optimizing available natural resources and recycling of materials based on the training of public high school students and teachers. The dialogical sharing among students of both education institutions enabled experimentation with new modes and actions to solve problems such as storage of rainwater, composting of school lunch leftovers and reuse of recycled materials to make a hydroponic system for the cultivation of vegetables and medicinal plants.

Keywords: Rainwater; Composting; Hydroponics; Reuse
Originais recebidos em

29 de julho de 2019

Aceito para publicação em

09 de abril de 2020

1

Engenheiro Agrônomo, docente do Centro de Ciências da Natureza, Universidade Federal de São Carlos (UFSCar) campus Lagoa do Sino. danielbaron@ufscar.br (autor para correspondência)

2 Biólogo(a), professor(a) da Escola Estadual Ivens Vieira município de Angatuba-SP. cgmomberg@gmail.com scoalmeida@gmail.com

\section{3}

Pedagoga, formação continuada de docentes da UFSCar Universidade Federal de São Carlos (UFSCar) campus São Carlos. meire@ufscar.br; eahelmer@gmail.com 


\section{Introdução}

De forma geral, as universidades brasileiras buscam a integração de diversas áreas de conhecimento, de modo a fomentar ações conjuntas que possam gerar novos conhecimentos que transcendam os limites das áreas tradicionais e, muitas vezes, adotam políticas que estimulam a integração entre estudantes, docentes, e servidores técnico-administrativos para o desenvolvimento de projetos institucionais multidisciplinares. No ano de 2002, a Universidade Federal de São Carlos (UFSCar) criou uma modalidade acadêmica curricular intitulada 'Atividades Curriculares de Integração entre Ensino, Pesquisa e Extensão' (ACIEPE) com o propósito de produzir, sistematizar e difundir conhecimento, desenvolvendo suas atividades de pesquisa e ensino interligadas com as demandas dos setores externos por meio de ações de extensão trabalhadas de maneira indissociável, a fim de possibilitar a consolidação do 'tripé' ensino/pesquisa/extensão (Souza \& Gil, 2016).

Aprender o conceito de indissociabilidade entre ensino, pesquisa e extensão tem se tornado uma constante busca para a compreensão da função e papel das universidades, em que pese o princípio irrevogável frente ao desafio de construirmos uma universidade de excelência associada ao compromisso social. A partir de práticas extensionistas, os autores deste estudo iniciaram uma atividade didática cuja proposta central foi envolver estudantes e docentes do ensino médio da Rede Pública de Ensino, docentes e discentes dos cursos de graduação em Engenharia Ambiental e Engenharia Agronômica, de maneira integrada, a fim de se desenvolver atividades práticas sustentáveis para sua posterior implantação nas dependências de Escolas da Rede Pública de Ensino.

A importância atribuída à tarefa de expandir e consolidar o conhecimento público sobre educação ambiental, contínua e ativamente, visa desenvolver a plena consciência da necessidade de se manter o ambiente o mais sustentável possível vem se alargando consideravelmente nos últimos anos no Brasil e, neste sentido, já é possível identificar que algumas IES (Instituições de Ensino Superior) apresentam algumas iniciativas que induzem à preservação do meio ambiente, gerando um compromisso diário com a causa (Rauen et al. 2015), quer pelo avanço da ciência e da tecnologia, quer por motivos políticos, ideológicos ou educacionais. Ao extrapolarmos para o cenário internacional, o desenvolvimento científico e tecnológico tem introduzido novos temas de pesquisa, que foram levados à pauta não só para o debate na sociedade, mas também para o aprimoramento de profissionais ligados à educação. Grande parte do debate refere-se à relação do homem com o meio ambiente, notadamente à sua sustentabilidade (Ocetkiewicz et al., 2017; Valderrama-Hernández et al., 2017; Mróz et al., 2020).

Desde o final do milênio passado, diversos conceitos e reflexões sobre a relação entre práticas urbanas/agrícolas e o desenvolvimento sustentável se tornaram não somente uma base teórica, mas também importante norma social para o desenvolvimento humano por todo o planeta, visando fomentar técnicas para o reaproveitamento de águas pluviais, o combate ao desperdício de alimentos junto à reutilização de resíduos orgânicos, e a diminuição da contaminação de alimentos por excesso de produtos químicos, entre outras (Freitas et al., 2013; Dos Anjos et al., 2018; El Tugoz et al., 2019). Tais iniciativas são apontadas como prioritárias para a equidade social, diversidade cultural e conservação do meio ambiente. Todavia, a sustentabilidade necessita de um entendimento mais amplo, que englobe o relacionamento entre os seres humanos e o meio ambiente, promovendo o conhecimento, a prática e os valores humanos para implementar relações pacíficas, racionais e saudáveis entre as populações, e dessas com o meio ambiente global e seus recursos naturais (Machado et al. 2015; Monavvarifard et al., 2019; Wallace et al., 2020).

Águas pluviais são uma fonte valiosíssima deste precioso bem em nosso Planeta, e técnicas eficazes na coleta dessas águas são de extrema importância, dado que a água doce é um recurso finito e vulnerável (BocanegraMartínez et al., 2014). Essas águas, frequentemente subaproveitadas nos centros urbanos, podem ser 
perfeitamente captadas e destinadas à irrigação de jardins, descargas de vasos sanitários, lavagem de roupas, ruas e calçadas, irrigação de hortas alimentares e medicinais, entre outros usos (Campisano \& Modica, 2012). Além dos aspectos positivos já mencionados no uso de sistemas de aproveitamento de água pluvial, o uso de técnicas na sua captação possibilita ainda redução no consumo de água potável, diminuição nos custos de água fornecida pelas companhias de abastecimento, minimização de riscos de enchentes e preservação do ambiente (Abdulla \& Al-Shareef, 2009; Sepehri et al., 2018; Wanjiru \& Xia, 2018).

Diante do atual cenário nacional e mundial na busca por uma sociedade mais consciente e atuante sobre a Sustentabilidade, emerge também como necessidade a "Biodiversificação dos sistemas de produção agrícolas" e, entre estes sistemas de produção, são excelentes opções a compostagem de sobras alimentares (Komakech et al., 2016; Nigussie et al., 2016; Boruah et al., 2019) e o cultivo hidropônico de hortaliças (Furlani et al., 1999; Martinez, 2002; Son et al., 2016). A compostagem é um método muito empregado nos últimos tempos, pois utiliza restos de produtos orgânicos para posteriormente incorporar ao solo, visando aprimorar suas capacidades físicas e químicas, em busca de plantas alimentícias mais saudáveis e com menor dependência de fertilizantes industriais (Diniz Filho et al., 2007). Isto possibilita, por exemplo, destinação sustentável aos resíduos orgânicos, como restos alimentares de merenda escolar.

Já o cultivo hidropônico é uma opção que atende perfeitamente aos anseios atuais da sociedade, pois tratase de técnica não apenas utilizada para investigação hortícola e produção de vegetais, mas também empregada como ferramenta para resolver um amplo leque de problemas, que incluem a redução da contaminação do solo, a manipulação dos níveis de nutrientes utilizados no cultivo vegetal, além de possibilitar o estudo de forma multidisciplinar de inúmeros aspectos vegetais e ambientais (Tanaka et al., 2016; Armanda et al., 2019; Magwaza et al., 2020).

De maneira geral, estudantes, professores e técnicos universitários no Brasil não são estimulados a elaborarem e executarem projetos de extensão. Não obstante, as comunidades universitárias que possuem interesse e aptidão, esbarram na grande dificuldade de financiamento para estas atividades no âmbito universitário. Muitas vezes, a tecnologia gerada na universidade acaba se restringindo ao uso e benefício diretamente dos próprios estudantes do ensino superior e pesquisadores, sem a preocupação em se difundir e popularizar tais conhecimentos.

Diante deste panorama, esta pesquisa teve como objetivo analisar contextos de aprendizagem propiciados por um projeto de colaboração universidade-escola, empregando como tema norteador das atividades os conceitos teóricos sobre a técnica da hidroponia e biodiversificação na produção de hortaliças, de modo sustentável.

\section{Metodologia}

A partir da Atividade Curricular de Integração entre Ensino, Pesquisa e Extensão (ACIEPE), intitulada 'Difundindo e popularizando a hidroponia sustentável pela UFSCar: Integração Ensino Médio-Graduação' (Proex-UFSCar, no. 23112.003596/2015-22), as atividades teórico-práticas foram orientadas entre o período de 08/03/2016 a 30/08/2016 (aproximadamente 6 meses) e, neste período, realizados 15 encontros presenciais, com duração de 4 horas por encontro. As atividades dessa ACIEPE foram realizadas com a participação de 01 docente efetivo do magistério superior e 12 estudantes regularmente matriculados nos cursos de graduação em Engenharia Agronômica e/ou Engenharia Ambiental pertencentes à Universidade Federal de São Carlos (UFSCar) campus Lagoa do Sino (Buri/SP); 20 estudantes do ensino médio e 06 docentes do ensino médio pertencentes à Escola Estadual Ivens Vieira (Angatuba/SP), de modo que situadas em municípios distintos a distância geográfica entre as duas instituições de ensino é de $25 \mathrm{~km}$. 
O percurso metodológico foi totalmente pautado pela construção de um ambiente de troca de informações, um 'laboratório' com múltiplas 'lentes' a fim de se levar em consideração os mais variados pontos de vistas sobre a proposta de difundir e popularizar o tripé ensino-pesquisa-extensão gerado em universidades, de maneira que os protagonistas de todo o processo foram os próprios estudantes, de ambas as instituições, com os docentes atuando essencialmente como facilitadores do ensino-aprendizagem.

Ao longo desse período, os estudantes de ambas as instituições também se dedicaram a esta atividade em horários extra-classe, de modo que nestes horários adicionais ocorreram integrações somente entre estudantes da mesma instituição na universidade, ou na escola. Ao final de cada atividade de integração foram geradas atas, nas quais foram documentadas as discussões e avanços de cada um dos encontros.

Inicialmente, a primeira orientação feita aos estudantes do ensino superior UFSCar campus Lagoa do Sino pautou-se no tema hidroponia e biodiversificação de produção vegetal sustentável, sendo este tema apresentado pelos estudantes de graduação, em diálogo com os estudantes do ensino médio, com o intuito de construir possíveis sistemas sustentáveis, de acordo com a necessidade e demanda da Escola Ivens Vieira. Também foi acordado que a tutoria dos estudantes do ensino médio (realizada pelos estudantes universitários) fosse conduzida na própria Escola e, desta forma, foi necessário o deslocamento dos estudantes do ensino superior até a mesma.

Assim, realizou-se o primeiro encontro nas dependências da Escola Pública Ivens Vieira, em que os estudantes universitários optaram por utilizar uma linguagem mais simples e coloquial, apropriada para descomplicar o vocabulário técnico referente ao assunto. Nesta primeira integração entre os estudantes universitários e do ensino médio, foi realizada uma dinâmica de grupo 'quebra-gelo' centrada em uma breve apresentação (autoapresentação) de cada integrante, proporcionando-lhes assim a oportunidade de expor seus anseios e expectativas com relação ao desenvolvimento das atividades. Ao final desta apresentação, os estudantes universitários realizaram a exposição de possíveis propostas sobre sustentabilidade, bem como a demonstração com maquetes e atividades lúdicas sobre os principais temas sugeridos aos estudantes, tais como:

a) Sustentabilidade: contribuir para minimizar ao máximo os impactos ao meio ambiente naquele território;

b) Hidroponia Sustentável: esclarecer junto aos estudantes da Rede Pública de Ensino que, apesar do termo grego 'hidroponia' significar 'cultivo com água', plantas cultivadas apenas em água não representa desenvolvimento vegetativo, mas que cultivadas em soluções nutritivas estas fornecerão os nutrientes necessários que um vegetal necessita;

c) Material Reciclado: gerar o mínimo de resíduos e impactos ao meio ambiente, sendo assim plausível o uso de materiais recicláveis para a execução desta proposta;

d) Compostagem: desenvolver técnicas de reaproveitamento dos restos de alimentos gerados pela escola, a fim de produzir compostos orgânicos ricos em nutrientes essenciais para o cultivo de plantas nas dependências da Escola.

Seguem abaixo alguns dos questionamentos e reflexões elaborados pelos estudantes do ensino médio aos estudantes universitários, ao longo da apresentação dos temas:

Como forma a raiz sem a terra?

Compostagem: como ocorre o processo?

Existe quantidade certa de nutrientes na solução nutritiva?

Como saber quais nutrientes as plantas precisam?

Como funciona a respiração da raiz? 
Neste tipo de cultivo hidropônico, o vegetal resultante pode ser chamado de hortaliça orgânica?

Existe diferença no tempo de cultivo, entre sistema hidropônico e convencional?

No sistema hidropônico, é possível achar bichos na alface?

Com relação a fotossíntese, há diferença?

A água da solução nutritiva não precisa ser trocada?

Essas questões foram desenvolvidas pelos estudantes universitários, utilizando linguagem adequada e condizente com a idade e escolaridade dos estudantes do ensino médio. O diálogo construído entre os estudantes evoluiu de tal maneira que foi possível observar o enorme interesse dos estudantes da Escola Pública em aprender e conhecer mais sobre os assuntos inicialmente discutidos, de modo que ao final deste encontro pensou-se em outras opções possíveis de serem desenvolvidas nas dependências da Escola. Foi sugerido, por exemplo, o direcionamento da água da chuva em tambores colocados estrategicamente nas calhas para reaproveitamento no sistema hidropônico e no jardim, usar compostagem para o desenvolvimento de plantas olerícolas, e a utilização de material reciclável para a construção dos sistemas. A partir do que foi decidido na integração, os estudantes universitários se dividiram voluntariamente em equipes de trabalho com as seguintes características e atividades:

Equipe 'captação e armazenamento de águas pluviais'. Responsável pela captação e armazenamento de águas pluviais, desenvolveu as seguintes atividades: (i) apresentação da proposta de trabalho e levantamento desses dados com os estudantes do ensino médio; (ii) definição do índice pluviométrico do local de implantação do sistema sustentável; (iii) levantamento das dimensões da área de irrigação, com o uso da água pluvial captada e armazenada; (iv) levantamento da capacidade volumétrica dos tambores para armazenamento de água. Após a definição dos temas a serem trabalhados de forma conjunta, a próxima etapa consistiu em discutir sobre quais materiais poderiam ser utilizados na fabricação dos sistemas de captação e armazenamento da água, sendo que a opção adotada foi o reaproveitamento de materiais descartados (Tabela 1).

Tabela 1. Lista de materiais utilizados pela comissão 'captação de águas pluviais' durante as atividades práticas realizadas na Escola da Rede Pública de Ensino.

\begin{tabular}{cl}
\hline Quantidade & Material \\
\hline 04 & abraçadeira \\
03 & lixa de ferro \\
01 & arco de serra \\
01 & selador de calha \\
01 & bisnaga silicone \\
02 & torneiras $1 / 4$ de volta \\
01 & rolo de fita veda rosca \\
01 & $\mathrm{~m}^{2}$ tela de mosqueteira \\
02 & registro $1 / 4$ de voltas de 2" \\
01 & mangueira plástica preta/água (50 m) \\
04 & tambor de metal + tampa com capacidade volumétrica para $200 \mathrm{~L}$ \\
\hline
\end{tabular}


Na sequência, deu-se início à construção do referido sistema utilizando-se tubulação de plástico reciclado e tambores de metal descartados, com volume de 200 litros, com o propósito de armazenar o máximo volume de água coletada das chuvas. Estes tambores foram forrados na parte superior com duas camadas de tela tipo voal, para reter as impurezas e impedir a proliferação de mosquitos como Aedes aegypti. Além disto, foram inseridos na parte inferior dos tambores um registro para a entrada/saída de mangueira plástica de 2 polegadas de diâmetro. Estes tambores foram posicionados em pontos do telhado da Escola que possuem calhas com pontos de saída de água. A partir do desnível do próprio terreno, a água armazenada nos tambores é transferida pela ação natural da gravidade para pontos estratégicos, tais como jardim, pátios pavimentados, hortas, floreiras (Figura 1).

Equipe 'compostagem com resíduos orgânicos'. Esta equipe desenvolveu as seguintes atividades: (i) discussão sobre qual método de compostagem sustentável seria o mais eficiente dentre as alternativas disponíveis, ou desenvolver uma composteira feita com madeira descartada ou com plástico reciclável; (ii) confecção de duas composteiras pequenas, ambas de madeira (pallet) com tampa e outra sem tampa. Acordou-se pelo reaproveitamento de materiais descartados. Assim, deu-se início a construção dos dois tipos de composteiras: composteiras de plástico (baldes plásticos) e composteiras de madeira (pallets de madeira impróprios para uso em indústria); (iii) elaboração de listagem de materiais orgânicos passíveis de compostagem; (iv) germinação e emergência das mudas olerícolas (Tabela 2).

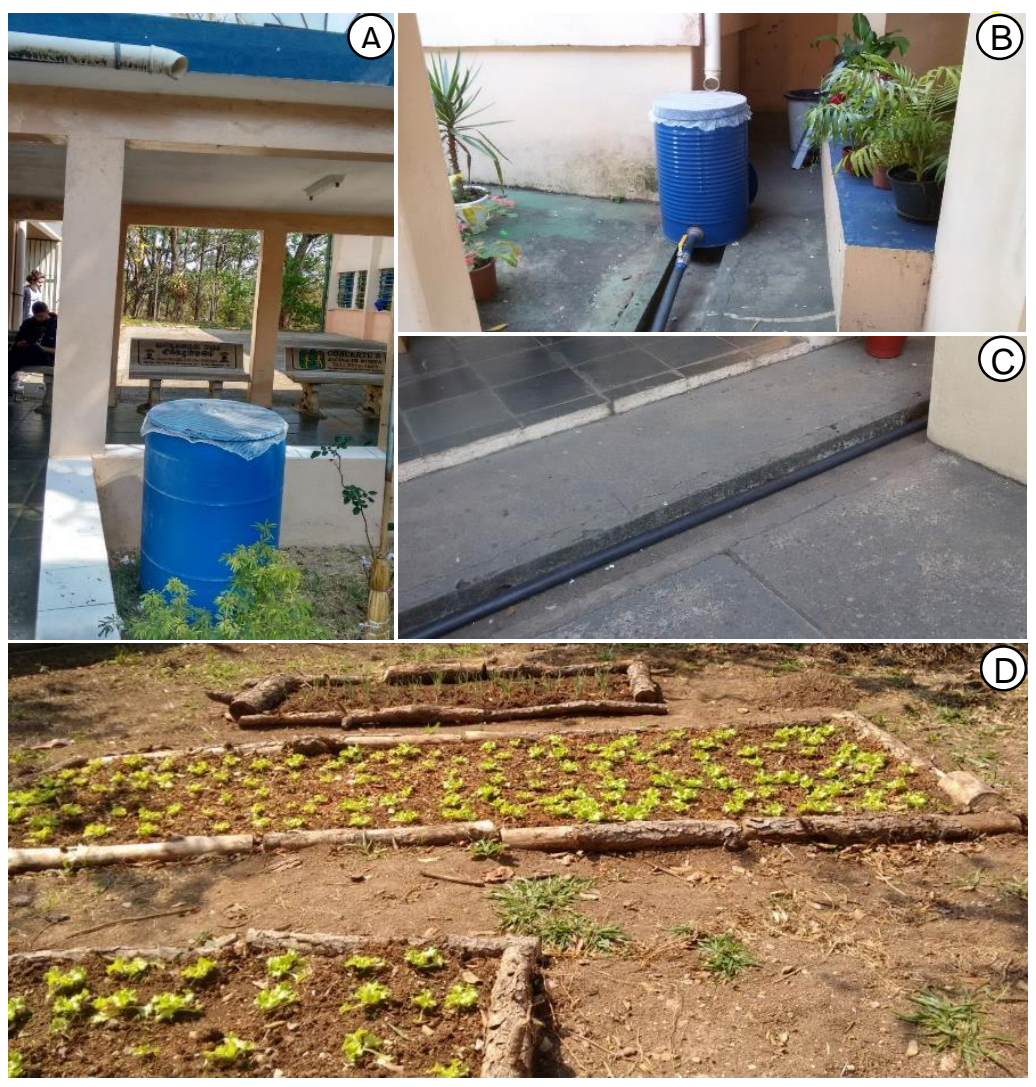

Figura 1. Preparo e instalação dos materiais recicláveis referentes ao sistema de captação de águas pluviais no pátio da Escola Estadual Ivens Vieira (Angatuba/SP). A, B. pontos de captação de água pluvial; C. mangueira para transferência da água, recolhida nos tambores, para os pontos de irrigação; $\mathbf{D}$. área de cultivo de hortaliças (horta) que recebe a água coletadas as chuvas. Crédito das imagens: C. G. Momberg da Silva. 
Tabela 2. Lista de materiais utilizados pela comissão 'compostagem de resíduos orgânicos' durante as atividades práticas realizadas na Escola da Rede Pública de Ensino.

\begin{tabular}{cl}
\hline Quantidade & Descrição do Material \\
\hline 01 & broca \\
\hline 01 & martelo \\
01 & serra elétrica \\
\hline 02 & torneira plástica \\
\hline 01 & pacote de prego \\
\hline 01 & regador (10 dm $\left.{ }^{3}\right)$ \\
\hline 01 & furadeira elétrica \\
\hline 01 & roçador de grama \\
\hline 01 & pacote de parafuso \\
\hline 01 & trena de 50 metros \\
\hline 01 & pacote de minhocas \\
\hline 02 & bandeja de poliestireno \\
\hline 05 & $\mathrm{~m}^{2}$ tela sombrite $(70 \%$ sombreamento $)$ \\
\hline 01 & saco de substrato para hortaliças $(25 \mathrm{~kg})$ \\
\hline 06 & baldes plásticos com tampa (dimensões: $20 \mathrm{~L})$ \\
\hline 10 & pallet de madeira $\left(0,80 \mathrm{~m} \times 0,60 \mathrm{~m} \times 0,50 \mathrm{~m}=0,24 \mathrm{~m}^{3}\right)$ \\
\hline & \\
\hline
\end{tabular}

A utilização de seis baldes plásticos descartados, previamente higienizados, foram empregados para a construção de duas composteiras plásticas (sistema dotado de três baldes para cada composteira). A montagem das mesmas consistiu em fazer diversos furos no fundo dos dois baldes superiores, bem como na tampa intermediária, com o auxílio de uma furadeira, e cortar o centro da tampa do balde que serviu de base, mantendo a tampa superior intacta. Após esse processo, colocou-se uma tela de proteção na tampa do último balde, para impedir a passagem das minhocas. No último balde foi instalada uma torneira de filtro que serviu de escoamento para o chorume (líquido formado durante o processo de decomposição da matéria orgânica). Por fim, os três baldes foram empilhados, finalizando o processo. O mesmo procedimento foi realizado nos demais baldes, obtendo-se assim dois sistemas completos de compostagem.

Para a confecção das composteiras de madeira, utilizou-se madeira de pallets descartados por indústria localizada na região. Definiu-se as dimensões das madeiras dos pallets passíveis de utilização para posteriormente serem lixadas. Com o auxílio de serrote, juntamente com o martelo e pregos, os pallets foram desmontados, selecionando as melhores partes para a formação das paredes da composteira, enquanto as madeiras mais grossas foram utilizadas na base, para que o recipiente não ficasse junto ao chão (Figura 2). 

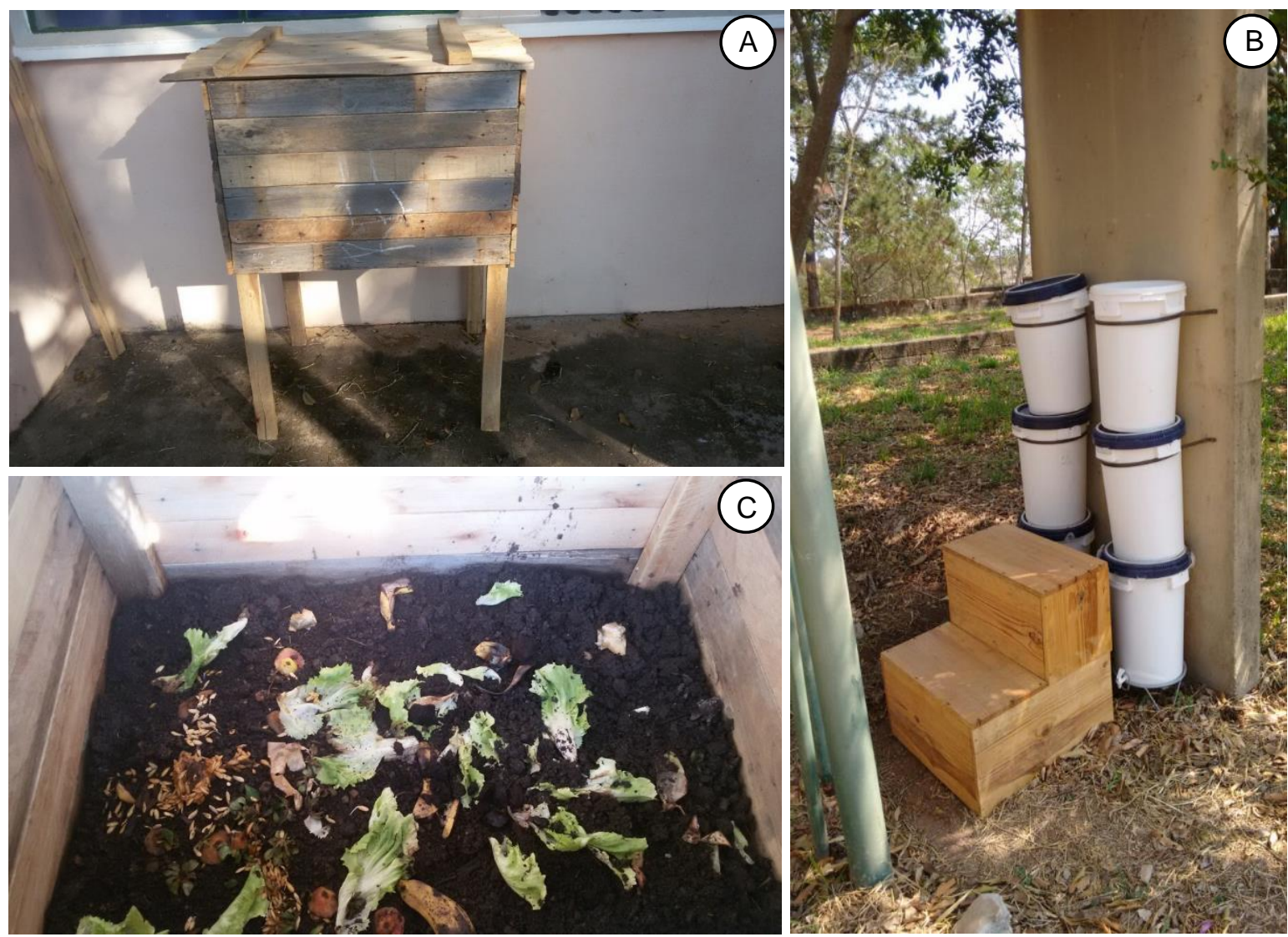

Figura 2. Preparo e instalação dos materiais recicláveis referentes ao sistema hidropônico no pátio da Escola Estadual Ivens Vieira (Angatuba/SP). A. composteira de madeira instalada em local adequado; B. composteiras de plástico instaladas em local adequado; C. resíduos orgânicos em compostagem instalada e monitorada pelos estudantes. Crédito das imagens: C. G. Momberg da Silva.

Ao final da montagem dos dois sistemas de compostagem, foram adicionadas minhocas da espécie Eisenia foetida Sav., conhecida popularmente como vermelha-da-califórnia. Para um bom desenvolvimento do minhocário, além de matéria-prima suficientemente rica para a alimentação, manteve-se as composteiras em local com acesso restrito de pessoas, com incidência de luz solar difusa e temperatura oscilando entre 20 e $25^{\circ} \mathrm{C}$ e umidade em torno de 55-70 \% (termo-higrômetro digital), além de aeração e drenagem do meio, o qual não deve ser compactado e nem encharcado (Aquino et al., 2009).

Equipe 'sistema hidropônico utilizando material reciclável'. A equipe utilizou material reciclável e desenvolveu as seguintes atividades (Tabela 3): (i) discussão de possíveis alternativas para a construção de sistema hidropônico sustentável, tipo NFT (técnica do filme nutriente), de forma horizontal e vertical, utilizando-se cano PVC descartado ou garrafas pet, (ii) definição sobre a possibilidade de cultivar duas espécies, morango e alface, em diferentes tipos de NFT.

Optou-se pela proposta mais apta em realizar nas dependências da Escola e, deste modo, iniciou-se a construção do referido sistema com utilização de materiais alternativos (reciclados), tais como abraçadeira de nylon, de metal e conexões de $1 / 2$ polegada. 
Tabela 3. Lista de materiais utilizados pela comissão 'Sistema hidropônico sustentável' durante as atividades práticas realizadas na Escola da Rede Pública de Ensino.

\begin{tabular}{cl}
\hline Quantidade & Descrição do Material \\
\hline 500 & ml de graxa \\
\hline 20 & lacre de plástico \\
\hline 06 & derivação "1/2 para $3 / 4$ " \\
\hline 60 & garrafas pet com tampa \\
\hline 01 & mangueira de jardim (50 m) \\
\hline 02 & placa de espuma de trapaceiro \\
\hline 04 & $\mathrm{~m}^{2}$ tela sombrite (70\% sombreamento) \\
01 & portão de ferro reutilizável (1,87 m x 0,87 m) \\
01 & kit hidroponia (preparo de solução nutritiva) \\
\hline
\end{tabular}

Equipe 'sistema hidropônico utilizando material reciclável'. A equipe utilizou material reciclável e desenvolveu as seguintes atividades: (i) discussão de possíveis alternativas para a construção de sistema hidropônico sustentável, tipo NFT (técnica do filme nutriente), de forma horizontal e vertical utilizando-se cano PVC descartado ou garrafas pet, (ii) definição sobre a possibilidade de cultivar duas espécies, morango e alface, em diferentes tipos de NFT (Tabela 3).

Optou-se pela proposta mais apta em realizar nas dependências da Escola e, deste modo, iniciou-se a construção do referido sistema optando-se por utilizar materiais alternativos (reciclados), tais como abraçadeira de nylon, de metal e conexões de $1 / 2$ polegada, bomba de aquário, estacas de bambu descartados, espuma descartada de tapeçaria, garrafas pet com volume de $2 \mathrm{dm}^{3}$, grades de metal sucateado, mangueira plástica de $1 / 2$ polegada, tela sombrite na cor preta ( $50 \%$ luminosidade) e tinta spray na cor prata opaca para revestimento externo das garrafas de plástico. As garrafas inicialmente foram pintadas na cor prata, com o propósito de evitar a entrada de luminosidade e a consequente proliferação de algas.

Após o preparo das garrafas, as mesmas foram conectadas entre si, com auxílio da mangueira plástica transparente. Grades de metal, as quais serviram de suporte para as garrafas plásticas, foram fixadas no local a ser implantado o sistema, sendo que as garrafas conectadas foram presas junto à grade com as abraçadeiras de nylon, de forma que fosse possível obter dois sistemas de distribuição do cultivo hidropônico, um destes em sentido inclinado e o outro no sentido vertical. Com as garrafas ligadas às grades, estimou-se a potência da bomba de água e, consequentemente, o posicionamento das mesmas ao lado do sistema (Figura 3). 


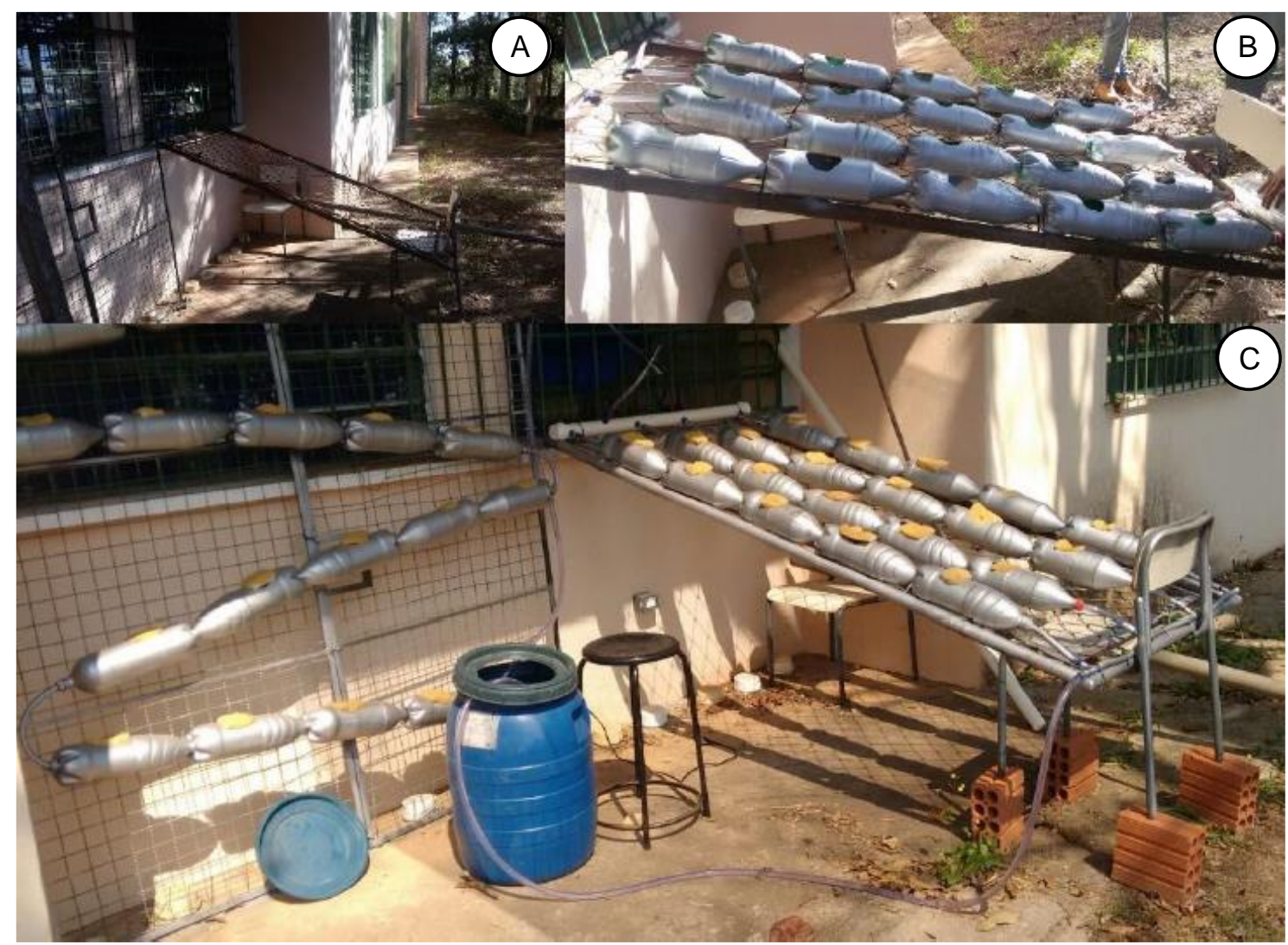

Figura 3. Preparo e instalação dos materiais recicláveis referentes ao sistema hidropônico no pátio da Escola Estadual Ivens Vieira (Angatuba/SP). A. grade de metal (portão) encontrado em ferro-velho; B. garrafas pet instaladas sobre a o portão de metal; $\mathbf{C}$. sistema hidropônico instalado e pronto para o cultivo das mudas de hortaliças. Crédito das imagens: C.G. Momberg da Silva.

Ao longo de todo o desenvolvimento prático das atividades, cada uma das três equipes de trabalho, chamadas apenas de 'comissões', contou sempre com os mesmos estudantes universitários que se voluntariaram para coordenar as atividades de acordo com o seu grau de afinidade. Todavia, os estudantes do ensino médio revezaram-se entre as assim chamadas 'comissões', pois entenderam ser melhor para o seu aprendizado a vivência da experiência como um todo por meio de uma colaboração em regime de rodízio por todas as atividades desenvolvidas pelas diferentes equipes. $O$ encerramento oficial desta etapa foi realizado com a devolutiva dos avanços e aprendizados dos estudantes do ensino médio, tanto nas dependências da Escola quanto da Universidade. Inicialmente, os estudantes do ensino médio apresentaram, de maneira dinâmica durante todos os períodos de aula, as ações sustentáveis geradas nas dependências de sua Escola, expondo os avanços obtidos a todos os docentes, discentes, servidores técnico-administrativos, pais e responsáveis, a partir das 'estações' de visita aos pontos de captação de água, compostagem e produção hidropônica. Além disso, maquetes (montadas incialmente pelos estudantes universitários) foram empregadas como roteiros, juntamente com painéis e projeção em tela com fotos dos protótipos construídos na Escola. Após estas inúmeras apresentações orais à comunidade, as maquetes foram utilizadas pelos estudantes universitários e do ensino médio para posterior apresentação também nas dependências da universidade à toda comunidade local (servidores-docentes, servidores-administrativos e discentes).

Por fim, ao término das atividades integradas, foi solicitado aos participantes que avaliassem o trabalho realizado por meio de seu depoimento sobre as atividades desenvolvidas. 


\section{Resultados e Discussão}

Através desta proposta, os estudantes da Escola Estadual, com o auxílio dos estudantes universitários, a partir de exposição teórica de tópicos sobre nutrição mineral de plantas, cultivo hidropônico e preparo de soluções nutritivas, adquiriram informações e conhecimentos necessários para desenvolver um sistema sustentável, a fim de atender as demandas da referida Escola, especialmente quanto ao reaproveitamento de água das chuvas e cultivo hidropônico sustentável utilizando materiais inicialmente descartados sem destinação certa. Somado a estas ideias inovadoras, os estudantes da Escola da Rede Pública de ensino que participaram desta atividade partiram para a produção própria de composteiras visando o reaproveitamento de sobras de alimentos oriundos da merenda escolar, a fim de que a compostagem gerada pelas mesmas fosse utilizada na implantação e condução.

Os discentes disseminaram pela comunidade informações e conhecimentos assimilados durante a execução desta ACIEPE para a comunidade, mostrando a relação e a articulação entre captar água da chuva, realizar a compostagem e o cultivo de hortaliças em sistema hidropônico. A água coletada foi reaproveitada para limpeza do pátio e irrigação do jardim da escola, além de despertar consciência socioambiental nos estudantes ao mostrar que todos podem incentivar a implantação deste hábito em seus próprios lares. O composto orgânico produzido com a compostagem foi reaproveitado para a produção de mudas de hortaliças e, em certa medida, norteou a escola sobre a importância em destinar adequadamente sobras de alimentos passíveis de compostagem oriundos da própria escola, para benefício dela mesma ao produzir hortaliças de forma sustentável. Quanto ao sistema hidropônico sustentável, oportunizamos aos estudantes o aprendizado e consciência de uma técnica diferenciada de cultivo, a qual integra e completa o 'ciclo virtuoso' para a produção de alimentos com a otimização dos recursos naturais.

Cabe lembrar que todas as etapas, desde o planejamento à execução desta proposta, foram realizadas de maneira integrada e dialogada entre os estudantes universitários e os estudantes do ensino médio da Rede Pública de Ensino. Esta abordagem deve ser ressaltada como uma importante estratégia na integração entre os estudantes da Rede Pública de Ensino e os estudantes do Ensino Superior, pois foi possível diagnosticar um enorme potencial de criatividade, responsabilidade, comprometimento e idealização de um futuro mais sustentável e menos agressivo ao ambiente entre todos os estudantes envolvidos.

Ao final das atividades integradas, os participantes manifestaram, voluntariamente, seu depoimento sobre a atividade desenvolvida, conforme relatos a seguir.

Estudantes universitários:

Esta atividade foi de grande valia, pois propiciou um enorme aprendizado tanto para a comunidade externa, quanto para a comunidade acadêmica, visto que permitiu levantar as demandas sobre a temática sustentabilidade da Escola Estadual e, a partir disso, pensar em possíveis soluções para sanar as mesmas.

Por meio de um sistema sustentável foi possível integrar três grandes processos que funcionaram como uma engrenagem, pois um processo depende do bom funcionamento do outro. A água recolhida das chuvas foi utilizada para irrigar o jardim da escola, lavar o pátio e principalmente, ser usada no sistema de cultivo hidropônico, além de que as mudas usadas neste sistema foram cultivadas com o adubo orgânico gerado a partir da compostagem, e desta forma se fez possível atender as necessidades da comunidade.

Através desta proposta de trabalho tivemos a oportunidade de estabelecer uma relação mutualística com a sociedade, na qual fomos beneficiados com a transferência de conhecimento em ambos os lados. 
O ponto importante a ser ressaltado é o fato de mostrarmos aos estudantes da Escola Estadual que a Universidade é um espaço aberto, na qual todos podem e têm o direito e capacidade de usufruir. As experiências de trabalho em grupo e de integração com os estudantes da Escola Estadual foram bastante produtivas e nos sentimos orgulhosos pelo resultado.

Minha sugestão é que essa proposta de atividade alcance mais escolas públicas, podendo assim disseminar as ideias de sustentabilidade e despertar mais consciência sustentável nos estudantes e mantenha esse vínculo com a referida Escola Estadual, mantendo os vínculos e atividades em constante andamento.

Estudantes do ensino médio:

O projeto nos permitiu agregar ensinamentos vindos do contato com alunos da faculdade, presenciamos um contato com a natureza e isso me motivou ainda mais a agir a favor do meio ambiente. Além desse contato, o que mais gostei também, foi poder apresentar aos alunos nosso trabalho. Assim como motivou cada participante, com certeza, chamou a atenção de muitos.

Esta proposta permitiu que eu ampliasse minha relação com as pessoas, me fez perder a timidez. $\mathrm{O}$ contato com a natureza me fez perceber o quão ela é bela, contudo, em mim nasceu o desejo de fazer mais a seu favor. Antes costumava jogar lixo na rua e hoje quando estou prestes a praticar esse ato, logo penso: Poxa, estou participando de um projeto de sustentabilidade e ainda vou contribuir em preservar o meio ambiente!

Esta integração pode ser constatada no depoimento do estudante abaixo:

O ponto importante a ser ressaltado é o fato de mostrarmos aos estudantes da Escola Estadual que a Universidade é um espaço aberto, na qual todos podem e têm o direito e capacidade de usufruir. As experiências de trabalho em grupo e de integração com os estudantes da Escola Estadual foram bastante produtivas e nos sentimos orgulhosos pelo resultado (A.L.N.R., Estudante do Curso de Engenharia Ambiental).

Tal proposta também evidenciou que os estudantes do campus Lagoa do Sino possuem extrema habilidade na condução das atividades práticas, bem como a capacidade de sanar dificuldades enfrentadas no desenvolvimento desta atividade que inevitavelmente ocorrem além da sala de aula, o que de certo modo permitiu a estes estudantes universitários e aos estudantes da Rede Pública de Ensino serem protagonistas nas ações realizadas e nos resultados obtidos. A partir das atividades desenvolvidas nas dependências da Escola, obteve-se um sistema de captação e armazenagem de água das chuvas, compostagem e sistema hidropônico eficientes e a baixo custo para atender a demandas locais, o que perfeitamente se configura como modelos válidos para emprego por toda a comunidade local. É possível identificar esta compreensão na avaliação de um dos estudantes do curso de Engenharia Agronômica:

Por meio de um sistema sustentável foi possível integrar três grandes processos que funcionaram como uma engrenagem, pois um processo depende do bom funcionamento do outro. A água recolhida das chuvas foi utilizada para irrigar o jardim da escola, lavar o pátio e principalmente, ser usada no sistema de cultivo hidropônico, além de que as mudas usadas neste sistema foram cultivadas com o adubo orgânico gerado a partir da compostagem, e desta forma se fez possível atender as necessidades da comunidade (G.H.P.M., Estudante do Curso de Engenharia Agronômica).

As ações realizadas a partir da integração ensino superior/ensino-médio possibilitaram uma relação de troca de saberes. $\mathrm{O}$ ambiente amistoso e acolhedor gerado entre as Instituições proporcionou trocar experiências do dia-a-dia dos estudantes do ensino médio, bem como a vivência acadêmica universitária, estimulando o debate de temas voltados à sustentabilidade. Assim, formou-se um olhar crítico para a realidade, e acerca da necessidade de se levar à comunidade no entorno da Escola o aprendizado construído ao longo das atividades 
extra-classe. A partir do início das atividades e durante os encontros entre os estudantes universitários e da Escola Estadual, concluiu-se que as ideias estabelecidas, levando-se em consideração a sustentabilidade e o meio ambiente como temas norteadores, se mostraram prontamente aceitas e extremamente viáveis para a difusão de conhecimentos, utilizando materiais alternativos, recicláveis e inovadores, visando encurtar as distâncias entre o conhecimento produzido nas universidades e a realidade das escolas e, consequentemente, da população em geral.

As ideias sobre o real significado de sustentabilidade e otimização dos recursos naturais apresentadas pelos estudantes universitários, de forma conjunta e dialogada, somaram-se às ideias e anseios dos estudantes do ensino médio e, surpreendendo positivamente todas as expectativas, os estudantes do ensino médio tomaram a iniciativa de confeccionar os sistemas necessários ao cultivo hidropônico sustentável e avaliar outras opções que preencheriam lacunas detectadas na Escola, tais como a construção de um sistema de captação e armazenamento de águas pluviais para posterior reaproveitamento na implantação e condução de hortaliças, plantas medicinais e plantas alimentícias não convencionais (PANC), bem como na irrigação de áreas verdes na Escola. Assim, o desafio da sustentabilidade não se restringe somente a questões ambientais, mas nas esferas econômicas e sociais, uma vez que busca garantir a satisfação das necessidades atuais, sem comprometer o meio ambiente e criar maiores dificuldades para as gerações futuras.

De acordo como Ruiz et al. (2019), atualmente há grande interesse em sistemas de produção sustentáveis com mínimo prejuízo ao ambiente, em especial aqueles que se destinam ao que pode ser cultivado em pequenas áreas, como é o caso das hortaliças. Tal aspecto corrobora a ferramenta metodológica empregada em nosso presente estudo, uma vez que muitos dos estudantes do ensino médio da rede pública são oriundos de áreas rurais (dados não mostrados) e, tal estratégia didática, permitirá aos estudantes incentivar seus pais ou responsáveis a consumirem alimentos produzidos em acordo com o tripé marcado pela viabilidade econômica, equilíbrio ecológico e equidade social.

Não obstante, estudos publicados por Fernandes e colegas (2013) e El Tugoz e colaboradores (2019) enfatizaram que o principal recurso natural utilizado na produção de alimentos é a água e, a partir da necessidade de uso consciente deste valioso recurso, torna-se necessário adotar estratégias e políticas públicas voltadas à promoção de práticas sustentáveis. Ainda sobre a necessidade de maior conscientização da sociedade como um todo acerca do uso racional deste recurso tão precioso, que é a água, em certa medida, nós podemos inferir, ainda, ser papel da Escola despertar em seus estudantes a real necessidade de se consumir alimentos produzidos a partir de técnicas de cultivo menos agressivas, ou que aproveitem águas pluviais, por exemplo, com o uso de cisternas. Nossa presente atividade propiciou aos estudantes um ambiente de estudo e realização de atividades práticas de forma colaborativa e participativa, a fim de que adquirissem os mesmos adquirissem certa autonomia na construção coletiva de ações em prol da sustentabilidade ao seu redor. Este tipo de abordagem possui respaldo em outras publicações com enfoque similares aos do presente estudo, e o envolvimento de discentes como 'futuros agentes de desenvolvimento' com efeito 'disseminador ou multiplicador' de ideias sustentáveis contempla, de forma qualificada.

De acordo com Machado e colegas (2015), inúmeras escolas já possuem áreas destinadas ao cultivo e produção de alimentos e isso tende a proporcionar uma relevante oportunidade de ensino/aprendizagem, considerando a importância de hortas no contexto educacional, contudo, esta ferramenta metodológica não está sendo utilizada no processo de educação integral dos estudantes na medida em que, lamentavelmente, estão desativadas para a produção de alimentos saudáveis para toda comunidade escolar.

Já ao que se refere aos 'extramuros' das instituições públicas de ensino, Dos Anjos e colegas (2018) reportam em uma comunidade de agricultores familiares a sensibilização dos moradores para uma consciência ambiental, associada à difusão de tecnologias para a conservação e manutenção de nascentes nas 
propriedades rurais, propiciando a construção de um pensamento crítico e consciente em relação a água por parte da população, servindo ainda de subsídio para a realização de saneamento rural e conservação de recursos hídricos. Os mesmos autores argumentam que a capacitação e instrução de jovens e adultos envolvidos, tornando-os aptos a difundir e disseminar informações técnicas, são fundamentais para uma transmissão horizontal do conhecimento.

De maneira geral, a presença de áreas verdes em ambientes públicos, seja uma escola, seja uma praça pública ou áreas particulares, certamente contribui para tornar o ambiente de convívio mais agradável, harmônico aos sentidos humanos e, até mesmo, se tornar um ambiente não formal de ensino, contudo estas vantagens não se consolidam na maioria das vezes. A partir deste cenário, Freitas e colegas (2013) apontam que a implantação e manutenção dessas áreas verdes em ambiente escolares, por exemplo em creches públicas, exige o enfrentamento de alguns desafios para sua consolidação. Os mesmos autores afirmam que o contato das crianças com os alimentos no seu ambiente de produção e consumo contribuíram para a sensibilização quanto à alimentação saudável e despertaram nos profissionais de ensino o interesse no trabalho pedagógico em práticas sustentáveis de cultivo.

\section{Considerações finais}

Os objetivos desta proposta em instalar sistema de cultivo hidropônico sustentável, utilizando a água recolhida da chuva para seu funcionamento, associado ao processo de compostagem a fim de contornar um problema de desperdício de alimentos enfrentado na Escola estadual foram atingidos com êxito. Acreditamos, também, que os objetivos não só foram atingidos, mas, inclusive, superados dentro das expectativas de todos os participantes, pois não apenas executamos a proposta inicial de hidroponia sustentável, mas também desenvolvemos atividades de compostagem e captação da água da chuva contribuindo ainda mais para a sustentabilidade.

\section{Agradecimentos}

A equipe deste estudo agradece aos estudantes da UFSCar campus Lagoa do Sino (Buri/SP) matriculados voluntariamente na 'Atividade Curriculares de Integração Ensino, Pesquisa e Extensão' (ACIEPEs), Proex-UFSCar Processo no. 23112.003596/2015-22, aos discentes e docentes da Escola Estadual Ivens Vieira (Angatuba/SP) pelo comprometimento, organização e por não medirem esforços na realização desta atividade extensionista.

\section{Contribuição de cada autor}

Os autores D.B., C.G.M.S., M.M.C. e S.C.O.A. participaram da elaboração do projeto, execução das atividades práticas e na interpretação dos resultados. D.B. atuou como coordenador principal entre a Instituição de Ensino Superior (UFSCar campus Lagoa do Sino) e a Escola da Rede Pública de Ensino (E.E. Ivens Vieira). Os autores D.B., C.G.M.S. e E.A.H. participaram da redação do texto.

\section{Referências}

Abdulla, F. A., \& Al-Shareef, A. W. (2009). Roof rainwater harvesting systems for household water supply in Jordan. Desalination, 243(1-3), 195-207.

Aquino, A. M. de. (2009). Vermicompostagem. Seropédica: EMBRAPA. (Circular Técnica 29). 
Armanda, D. T., Guinée, J. B., \& Tukker, A. (2019). The second green revolution: Innovative urban agriculture's contribution to food security and sustainability - A review. Global Food Security, 22, 13-24.

Bocanegra-Martínez, A., Ponce-Ortega, J. M., Nápoles-Rivera, F., Serna-González, M., Castro-Montoya, A. J., \& ElHalwagi, M. M. (2014). Optimal design of rainwater collecting systems for domestic use into a residential development. Resources, Conservation and Recycling, 84, 44-56.

Boruah, T., Barman, A., Kalita, P., Lahkar, J., \& Deka, H. (2019). Vermicomposting of citronella bagasse and paper mill sludge mixture employing Eisenia fetida. Bioresource Technology, 294, 122147.

Campisano, A., \& Modica, C. (2012). Optimal sizing of storage tanks for domestic rainwater harvesting in Sicily. Resources, Conservation and Recycling, 63, 9-16.

Diniz Filho, E. T., Mesquita, L. D., Oliveira, A. D., Nunes, C. G. F., \& Lira, J. D. (2007). A prática da compostagem no manejo sustentável de solos. Revista Verde de Agroecologia e Desenvolvimento Sustentável, 2(2), 27-36.

Dos Anjos, L. R. A., de Carvalho Maia, T., da Silva Queiroz, P. H., de Guimarães, F. S., Campos, R. A., Cardoso, T. F., \& de Sousa, W. L. (2018). Origem e histórico da" Rede Nós de Água": pesquisa, ensino e extensão participativa em conservação de recursos hídricos sob a perspectiva agroecológica. Revista ELO-Diálogos em Extensão, 7(1), 59-64.

El Tugoz, J., Bertolini, G. R. F., \& Brandalise, L. T. (2017). Captação e aproveitamento da água das chuvas: o caminho para uma escola sustentável. Revista de Gestão Ambiental e Sustentabilidade, 6(1), 26-39.

Fernandes, D. A., Gobbo, S. D. Â. A., Suhet, M. I., \& do Amaral, A. A. (2013). Uso da água e sustentabilidade da agricultura. Revista Verde de Agroecologia e Desenvolvimento Sustentável, 8(5), 101-107.

Monavvarifard, F., Baradaran, M., \& Khosravipour, B. (2019). Increasing the sustainability level in agriculture and Natural Resources Universities of Iran through students' engagement in the value Co-creation process. Journal of Cleaner Production, 234, 353-365.

Freitas, H. R., Gonçalves-Gervásio, R. D. C. R., Marinho, C. M., Fonseca, A. S. S., Quirino, A. K. R., Xavier, K. M. M. D. S., \& Nascimento, P. V. P. D. (2013). Horta escolar agroecológica como instrumento de educação ambiental e alimentar na Creche Municipal Dr. Washington Barros-Petrolina/PE. Extramuros-Revista de Extensão da UNIVASF, 1(1), $155-169$.

Furlani, P. R., Silveira, L. C. P., Bolonhezi, D., \& Faquin, V. (1999). Cultivo hidropônico de plantas. Campinas: IAC. (Boletim Técnico 180).

Komakech, A. J., Zurbrügg, C., Miito, G. J., Wanyama, J., \& Vinnerås, B. (2016). Environmental impact from vermicomposting of organic waste in Kampala, Uganda. Journal of Environmental Management, 181, 395-402.

Machado, J. T. M., Tonin, J., \& Schneider, E. P. (2015). Análise de ações extensionistas na implantação de hortas escolares de base ecológica, seus efeitos e desafios no contexto educacional. Revista Brasileira de Extensão Universitária, 6(2), 97-101.

Magwaza, S. T., Magwaza, L. S., Odindo, A. O., \& Mditshwa, A. (2020). Hydroponic technology as decentralised system for domestic wastewater treatment and vegetable production in urban agriculture: A review. Science of the Total Environment, 698, 134154.

Martinez, H. E. P. (2002). O uso do cultivo hidropônico de plantas em pesquisa. Viçosa: Editora UFV. (Cadernos didáticos).

Mróz, A., Ocetkiewicz, I., \& Tomaszewska, B. (2020). What should be included in education programmes - The socioeducation analysis for sustainable management of natural resources. Journal of Cleaner Production, 250, 119556.

Nigussie, A., Kuyper, T. W., Bruun, S., \& De Neergaard, A. (2016). Vermicomposting as a technology for reducing nitrogen losses and greenhouse gas emissions from small-scale composting. Journal of Cleaner Production, 139, 429-439.

Ocetkiewicz, I., Tomaszewska, B., \& Mróz, A. (2017). Renewable energy in education for sustainable development. The Polish experience. Renewable and Sustainable Energy Reviews, 80, 92-97.

Rauen, T. R., Lezana, Á. G. R., \& da Silva, V. (2015). Environmental management: An overview in higher education institutions. Procedia Manufacturing, 3, 3682-3688. 
Ruiz, A. S., Souza, S. V., \& Sabbag, O. J. (2019). Sustentabilidade em cultivos tradicional e hidropônico de alface. Revista em Agronegócio e Meio Ambiente, 12(3), 815-835.

Sepehri, M., Malekinezhad, H., Ilderomi, A. R., Talebi, A., \& Hosseini, S. Z. (2018). Studying the effect of rain water harvesting from roof surfaces on runoff and household consumption reduction. Sustainable Cities and Society, 43, 317324.

Son, J. E., Kim, H. J., \& Ahn, T. I. (2016). Hydroponic Systems. In G. Niu, \& M. Takagaki (Orgs.), Plant Factory. (pp. 213221). San Diego: Academic Press.

Souza, M. H. A. O. E., \& Gil, M. S. C. A. (2016). Diversificando Caminhos da Formação de Professores na UFSCAR - Algumas contribuições. São Carlos: Compacta.

Tanaka, Y., Kawashima, S., Hama, T., Sastre, L. F. S., Nakamura, K., \& Okumoto, Y. (2016). Mitigation of heating of an urban building rooftop during hot summer by a hydroponic rice system. Building and Environment, 96, $217-227$.

Valderrama-Hernández, R., Alcántara, L., \& Limón, D. (2017). The complexity of environmental education: Teaching ideas and strategies from teachers. Procedia-Social and Behavioral Sciences, 237, 968-974.

Wallace, K. J., Kim, M. K., Rogers, A., \& Jago, M. (2020). Classifying human wellbeing values for planning the conservation and use of natural resources. Journal of Environmental Management, 256, 109955.

Wanjiru, E., \& Xia, X. (2018). Sustainable energy-water management for residential houses with optimal integrated grey and rain water recycling. Journal of Cleaner Production, 170, 1151-1166.

Como citar este artigo:

Baron, D., Momberg da Silva, C. G. M., Almeida, S. C. O., Cordeiro, M. M., \& Helmer, E. A. (2020). Popularização da sustentabilidade: análise de uma integração ensino médio-graduação. Revista Brasileira de Extensão Universitária, 11(1), 97-112. https://periodicos.uffs.edu.br/index.php/RBEU/article/ view/10973/pdf 